\title{
Crescimento e Produtividade de genótipos de arroz de terras altas em Função de datas de Semeadura
}

Growth and Productivity of upland rice genotypes as a function of Sowing dates.

Crecimiento y Productividad de genotipos de arroz de tierras altas en Función de fechas de Sembradura.

Luiz Fernando Veroneis

Graduando em Engenharia Agronômica, Unesp - FCAT - Dracena, Brasil Luiz.veroneis@outlook.com

Samuel Ferrari Professor Doutor, Unesp - FCAT - Dracena, Brasil ferrari@dracena.unesp.br

Gustavo Henrique Veroneis Engenheiro Agrônomo, Unesp - Registro, Brasil. GustavoVeroneis3@hotmail.com 


\section{RESUMO}

O objetivo deste trabalho foi avaliar diferentes genótipos semeados em diferentes períodos do ano, avaliando crescimento e produtividade. $O$ estudo foi realizado na fazenda experimental da UNESP (Universidade Estadual Paulista) do Câmpus de Registro, SP. O delineamento experimental empregado foi o de blocos casualizados dispostos em esquema fatorial $4 \times 4$. Os tratamentos foram constituídos pela combinação de quatro genótipos de arroz em quatro épocas de semeadura, com quatro repetições totalizando 64 parcelas. Os genótipos selecionados para realização do experimento foram: ANA 7007, Moti Branco, Moti Amarelo e AN Cambará. As parcelas foram constituídas de cinco linhas com 5,0 $\mathrm{m}$ de comprimento cada, espaçadas em 0,35 m entre si totalizando uma área de $12,6 \mathrm{~m}^{2}$ cada parcela. Os genótipos apresentaram diferentes respostas, o AN Cambará demonstrou maior número de panículas por metro quadrado, o Moti Branco e Moti Amarelo apresentaram maiores altura de plântulas de arroz, o genótipo Moti Branco obteve a maior produtividade em todas as épocas de semeadura.

PALAVRAS-CHAVE: Oryza sativa L.; Produtividade; Baixa Fertilidade.

\section{ABSTRACT}

The objective of this work was to evaluate different genotypes sown in different periods of the year, evaluating growth and productivity. The study was carried out at the experimental farm of UNESP (Universidade Estadual Paulista) of Câmpus de Registro, SP. The experimental design was the randomized blocks arranged in a $4 \times 4$ factorial scheme. The treatments consisted of the combination of four rice genotypes in four sowing seasons, with four replications totaling 64 plots. The selected genotypes for the experiment were: ANA 7007, Moti Branco, Moti Amarelo and AN Cambará. The plots consisted of five lines with $5.0 \mathrm{~m}$ length each, spaced $0.35 \mathrm{~m}$ apart, totaling an area of $12.6 \mathrm{~m} 2$ each plot. The genotypes presented different responses, the AN Cambará showed a higher number of panicles per square meter, Moti Branco and Moti Amarelo presented higher height of rice seedlings, the Moti Branco genotype obtained the highest productivity in all sowing seasons.

KEY WORDS: Oryza sativa L .; Productivity; Low Fertility.

\section{RESUMEN}

El objetivo de este trabajo fue evaluar diferentes genotipos sembrados en diferentes períodos del año, evaluando crecimiento y productividad. El estudio fue realizado en la hacienda experimental de la UNESP (Universidad Estadual Paulista) del Cámpus de Registro, SP. El delineamiento experimental empleado fue el de bloques casualizados dispuestos en esquema factorial $4 \times 4$. Los tratamientos fueron constituidos por la combinación de cuatro genotipos de arroz en cuatro épocas de siembra, con cuatro repeticiones totalizando 64 parcelas. Los genotipos seleccionados para la realización del experimento fueron: ANA 7007, Moti Blanco, Moti Amarillo y AN Cambará. Las parcelas fueron constituidas de cinco líneas con 5,0 m de longitud cada, espaciadas en 0,35 m entre sí totalizando un área de 12,6 m2 cada parcela. Los genotipos presentaron diferentes respuestas, el AN Cambará demostró mayor número de panículas por metro cuadrado, el Moti Blanco y Moti Amarillo presentaron mayores altura de plántulas de arroz, el genotipo Moti Branco obtuvo la mayor productividad en todas las épocas de siembra.

PALABRAS CLAVE:. Oryza sativa L .; Productividad; Baja fertilidade. 


\section{INTRODUÇÃO}

O arroz (Oryza sativa L) está entre os cereais mais produzidos e consumidos no mundo, possuindo grande fonte de proteínas, calorias e vitaminas necessária para alimentação humana, sendo utilizado também na alimentação animal como auxilio em sua alimentação.

Pode ser utilizado como cultura inicial em novas áreas do cerrado, por suportar condições de solo de baixa fertilidade, solos ácidos e com alto teor de alumínio, condições com as quais outras culturas não suportariam tais condições para o seu desenvolvimento.

Este cereal faz parte da dieta básica de aproximadamente $50 \%$ da população mundial (LUZZARDI et al., 2005), podendo ser considerado o mais importante para a alimentação humana, pois, é consumido diretamente, enquanto outros cereais como o trigo e o milho são processados pela indústria, ou são utilizados na alimentação animal (SHEEHY et al., 2007).

É uma planta anual, adaptada a solos alagados, mas desenvolve-se bem em solos não alagados, e é formada de raízes, caule, folhas e panículas, que, na verdade, é um conjunto de espiguetas (GUIMARÃES et al, 2002).

O consumo de cereais, principalmente o arroz no Brasil é muito grande e tende a crescer cada vez mais devido ao aumento da população, sendo utilizados tanto para consumo quanto para produção de álcool, bebidas, acetonas, perfumes e vinagres entre outras.

Consequentemente há uma maior necessidade do aumento da produção não só por área mais também produtividade por hectares deste cereal.

O cultivo do arroz pode ser feito através de dois meios de produção, em várzeas podendo ser controlado através da irrigação ou alagamento, ou sem controle de água, ou pelo sistema de terras altas.

A época de semeadura das cultivares de arroz de sequeiro esta relacionada com o ciclo da cultivar, sendo ela de ciclo precoce, médio ou ciclo longo. A luminosidade, disponibilidade hídrica e temperatura oferecida para as plantas têm total interferência em seu ciclo.

Os genótipos que apresentem o ciclo mais longo devem ser semeados no final de setembro até meados de novembro, para que coincidam a floração e a granação com as épocas das chuvas, para que atinjam o seu potencial máximo.

A escolha da cultivar é uma das decisões determinantes do sucesso da lavoura, juntamente com a implantação de novas técnicas agronômicas e a aplicação das técnicas já conhecidas de forma correta. Novas cultivares de arroz são desenvolvidas buscando incorporar características que levem à maior produtividade, com alta qualidade e a um menor custo.

O conhecimento sobre as características climática da região, tipo de solo, incidência de pragas e doenças são fatores fundamentais a se conhecer para que a escolha da cultivar seja feita de forma efetiva a todas as características da região, podendo expressar seu potencial máximo.

A produtividade de uma cultivar não depende somente de seu potencial, mas também, das condições oferecidas para o seu desenvolvimento. O cultivo de terras altas, também conhecido como sistema de produção de sequeiro, resulta em baixa produtividade, quando comparado ao sistema de cultivo irrigado. Esta baixa produtividade pode ser atribuída à deficiência hídrica, durante o ciclo de desenvolvimento da cultura, estando, provavelmente, relacionada ao número de panículas por $\mathrm{m}^{2}$ e à fertilidade das espiguetas (CRUSCIOL et al., 2001).

\section{OBJETIVOS}


O Presente trabalho teve como objetivo avaliar genótipos de arroz de terras altas cultivados em diferentes épocas de semeadura quanto ao desenvolvimento vegetativo e produtividade de grãos.

\section{METODOLOGIA}

O experimento foi desenvolvido na área experimental da Fazenda de Ensino, Pesquisa e Extensão UNESP, Campus Experimental de Registro, SP, que apresenta altitude média de $25 \mathrm{~m}$, declividade entre 0 e $12 \%$ e clima do tipo Cfa subtropical úmido com verão quente, conforme a classificação de Koeppen, com temperatura média de $27^{\circ} \mathrm{C}$ e precipitação anual de $1500 \mathrm{~mm}$. O solo da área faz parte das Unidades dos Sistemas Ambientais, descrito como terrenos planos no Baixo Ribeira, de sedimentos modernos, em solos aluviais argilosos do tipo Cambissolo eutróficos em áreas de montante e Hidromórfico eutrófico em solos de planície.

As temperaturas e precipitações durante o período de agosto de 2012 e julho de 2013 estão disposta na Figura 1.

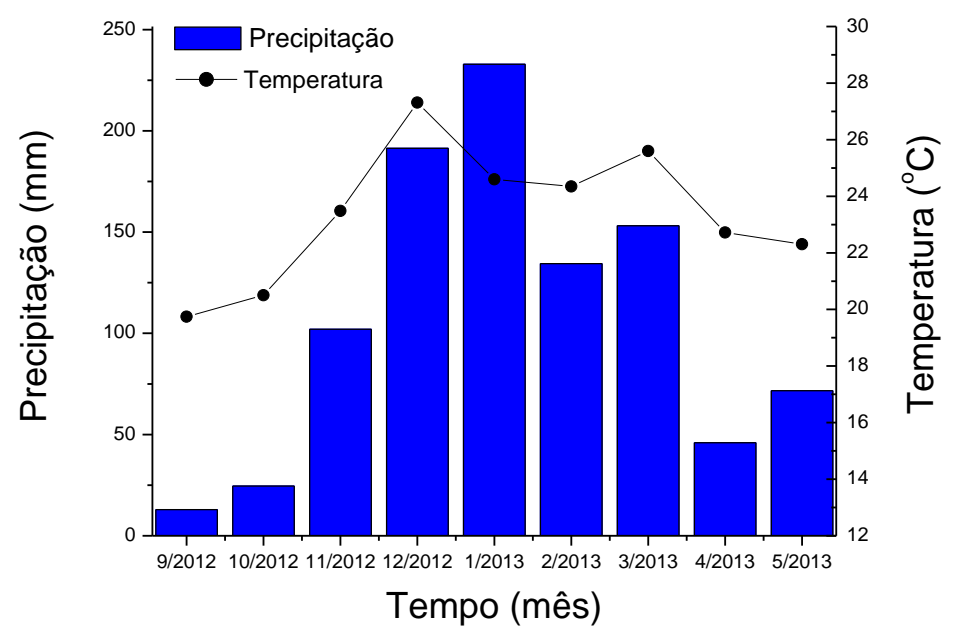

Figura 1. Temperatura e precipitação pluviométrica média em graus Celsius e milímetro respectivamente, dos meses de interferência no ciclo da cultura, (CIIAGRO Registro/SP, 2013).

Antes da instalação do experimento, em junho de 2012 foi realizada a coletada de uma amostra composta, originada de 20 amostras simples do solo de toda área experimental na profundidade de 0,0 - 0,20 m, revelando resultados apresentados na Tabela 1.

Tabela 1. Resultados da análise química do solo na profundidade de 0,0-0,20 m. Registro-SP, 2012.

\begin{tabular}{|c|c|c|c|c|c|c|c|c|c|c|}
\hline$P_{\text {resina }}$ & $S$ & \multirow{2}{*}{$\begin{array}{l}\text { M.O. } \\
\text { g/dm3 }\end{array}$} & \multirow{2}{*}{$\begin{array}{l}\mathrm{pH} \\
(\mathrm{CaCl} 2)\end{array}$} & K & $\mathrm{Ca}$ & $\mathrm{Mg}$ & $\mathrm{H}+\mathrm{Al}$ & Al & CTC & \multirow{2}{*}{$\begin{array}{l}\mathrm{V} \\
(\%)\end{array}$} \\
\hline \multicolumn{2}{|c|}{$\mathrm{mg} / \mathrm{dm} 3$} & & & \multicolumn{6}{|c|}{$\mathrm{mmolc} / \mathrm{dm} 3$} & \\
\hline 6 & 11 & 23 & 4,9 & 0,6 & 20 & 12 & 35 & 02 & 68 & 48 \\
\hline
\end{tabular}


$\mathrm{Na}$ área de pesquisa foi realizado o preparo convencional do solo, com arado de aiveca e subsolagem. A partir dos dados da análise de solo (Tabela 1), seguiu-se a recomendação de Raij e Cantarella (1997) aplicando $150 \mathrm{~kg} \mathrm{ha}^{-1}$ de calcário (PRNT 90), para a elevação da soma de bases para $50 \%$.

O delineamento experimental empregado foi constituído de blocos casualizados dispostos em esquema fatorial $4 \times 4$. Os tratamentos constituíram-se da combinação de quatro genótipos de arroz de terras altas em quatro épocas de semeaduras, com quatro repetições cada totalizando 64 parcelas.

Os genótipos utilizados nos ensaios foram: Moti amarelo - ciclo precoce, Moti branco - ciclo médio, Ana 7007 - ciclo precoce e Cambará - ciclo médio.

Ana 7007

Segundo a Agro Norte Pesquisas e Sementes (2013), a cultivar ANA 7007 possui um ciclo de 107 dias e com potencial genético para atingir 7 Ton./ha.

Por ser uma cultivar nova sendo lançado no ano agrícola de 2012 no mercado, não se tem muita informação, a respeito.

AN Cambará

Segundo Agro Norte Pesquisas e Sementes (2009), a cultivar AN Cambará possui uma ampla adaptabilidade, boa rusticidade, tem uma boa absorção de nutrientes quanto à adubação, fácil manejo dos tratos culturais, arquitetura de planta moderna, porte médio, resistente ao acamamento, com ciclo de 105 dias, bom, alto rendimento de grãos, sendo eles grãos translúcidos, ficando soltinho e macio logo após a colheita. Boa tolerância à brusone foliar, escaldadura, complexo de manchas foliares e manchas de grãos. Pode ser plantada em abertura de áreas, renovação de pastagens e terras velhas em rotação de culturas com soja. Características: porte: médio; espaçamento de plantio: 17 a $25 \mathrm{~cm}$; florescimento: 75 dias; tolerante ao acamamento.

Os Moti são muito utilizados principalmente pela cultura japonesa para fabricação de doces tradicionais. Há poucos estudos relacionados com o melhoramento genéticos dessa cultivar, mas o pouco que se conhece mostra o arroz Moti sendo fundamental para a cultura japonesa. Em suma, as cultivares Moti apresentam características de altura de planta maior que os genótipos desenvolvidos para melhor produção. A planta de arroz Moti pode chegar a dois metros de altura e por isso quando está com as panículas com os grãos cheios facilmente pode a um grande nível de acamamento.

A primeira época de semeada foi realizada no dia 22 de outubro de 2012, a segunda 19 novembro de 2012, a terceira dia 20 de dezembro de 2012 e a quarta no dia 14 de janeiro de 2013.

O tratamento das sementes dos diferentes cultivares de arroz foram realizados sempre no dia anterior à semeadura, sendo os defensivos utilizados: carboxina+tiram (vitavax thiram) ecarbofurano (furadam), nas dosagens (100 kg semente): $300 \mathrm{ml} \mathrm{p.c.} \mathrm{e} \mathrm{1,5} \mathrm{L} \mathrm{p.c.}$

As adubações de semeadura foram realizadas de forma manual. De acordo com a recomendação de Raij e Cantarella (1997), aplicou-se $600 \mathrm{~kg} \mathrm{ha}^{-1}$ do formulado 04-14-08. As adubações de cobertura ocorreram: a primeira aos 18 dias após a emergência (D.A.E.) aplicando-se $25 \mathrm{~kg} \mathrm{ha}^{-1} \mathrm{~N}$ na forma de sulfato de amônio (21\% N e $24 \% \mathrm{~S}$ ), a segunda adubação foi realizada aos 35 D.A.E. com $25 \mathrm{~kg} \mathrm{ha}^{-1} \mathrm{~N}$ na forma de $20-05-20$ e a terceira aos 50 D.A.E. com $20 \mathrm{~kg} \mathrm{ha}^{-1} \mathrm{~N}$ na forma de ureia.

As parcelas constituíram-se de cinco linhas, cada com 5,0 m de comprimento, espaçadas 0,35 $\mathrm{m}$ entre si totalizando $12,6 \mathrm{~m}^{2}$. A área útil de cada parcela se baseou nas três linhas centrais, sendo descartado 0,50 $\mathrm{m}$ em ambas as extremidades de cada linha. 
Foram realizadas avaliações de altura de plantas pela distância da superfície do solo até a extremidade superior da panícula mais alta aos 30, 60 e 90 D.A.E. ; diâmetro do colmo, mensurado com auxílio de paquímetro à altura de $1 \mathrm{~cm}$ em relação ao solo, por contagem direta. Essas avaliações foram realizadas utilizando-se de 10 plantas ao acaso, na área útil de cada parcela.

Tabela 2. Datas de semeadura, emergência, aparecimento de cacho coleta de folhas e colheita para os diferentes genótipos e épocas de semeadura.

\begin{tabular}{cc}
\hline Genótipos Semeadura Emergência & $\begin{array}{l}\text { Emissão da Colheita } \\
\text { panícula }\end{array}$
\end{tabular}

\begin{tabular}{lcccc}
\hline ANA 7007 & & & $08 / 01 / 2013$ & $11 / 02 / 2013$ \\
Cambará & & $17 / 01 / 2013$ & $25 / 02 / 2013$ \\
Moti Amarelo & $22 / 10 / 12$ & $29 / 10 / 12$ & $03 / 02 / 2013$ & $13 / 03 / 2013$ \\
Moti Branco & & & $05 / 02 / 2013$ & $13 / 03 / 2013$ \\
\hline ANA 7007 & & & $07 / 02 / 2013$ & $19 / 03 / 2013$ \\
Cambará & \multirow{2}{*}{$19 / 11 / 12$} & $29 / 11 / 2012$ & $13 / 02 / 2013$ & $21 / 03 / 2013$ \\
Moti Amarelo & & & $24 / 02 / 2013$ & $31 / 03 / 2013$ \\
Moti Branco & & & $28 / 02 / 2013$ & $31 / 03 / 2013$ \\
\hline ANA 7007 & & & $03 / 03 / 2013$ & $02 / 04 / 2013$ \\
Cambará & & & $05 / 03 / 2013$ & $15 / 04 / 2013$ \\
& & & & \\
Moti Amarelo & $20 / 12 / 12$ & $29 / 12 / 2012$ & $20 / 03 / 2013$ & $25 / 04 / 2013$ \\
Moti Branco & & & $20 / 03 / 2013$ & $25 / 04 / 2013$ \\
\hline ANA 7007 & & & $25 / 03 / 2013$ & $09 / 05 / 2013$ \\
Cambará & & & $09 / 03 / 2013$ & $11 / 05 / 2013$ \\
& & & & \\
Moti Amarelo & $14 / 01 / 13$ & $21 / 01 / 2013$ & $12 / 04 / 2013$ & $27 / 05 / 2013$ \\
Moti Branco & & & $11 / 04 / 2013$ & $27 / 05 / 2013$ \\
\hline
\end{tabular}

Os resultados foram submetidos à analise de variância pelo teste $\mathrm{F}$ ao nível de 5 e $5 \%$ de probabilidade e as médias comparadas pelo teste Tukey a $5 \%$ de probabilidade, utilizando o programa Sisvar.

\section{RESULTADOS}

Para a altura das plantas constatou-se que não houve diferença significativa na interação épocas e genótipos. $O$ genótipo Moti Amarelo obteve a maior altura de plantas, já o genótipo ANA 7007 a menor altura de planta, em relação às épocas de semeadura não obteve diferença entre na altura das plantas (Tabela 3). 
Tabela 3 Valores de p>F e teste de comparação de médias para altura de plantas, diâmetro do colmo, numero de folhas e numero de perfilhos avaliados aos 30 DAE dos cultivares de arroz em função de épocas de semeadura. Registro-SP, ano agrícola 2012/13.

\begin{tabular}{lllll}
\hline Teste F & Altura $(\mathrm{cm})$ & $\begin{array}{l}\text { Diâmetro }(\mathrm{mm}) \\
\text { p }\end{array}$ & \multicolumn{1}{l}{ Folhas (un) } & $\begin{array}{l}\text { Perfilhos } \\
\text { (un) }\end{array}$ \\
\hline Genótipo (c) & 0,1342 & 0,9338 & 0,5475 & 0,0981 \\
Época (e) & 0,5400 & 0,0020 & 0,0610 & 0,0000 \\
c*e & 0.1342 & 0,1283 & 0,5686 & 0,0647 \\
\hline \hline Moti Branco & $35,42 \mathrm{~b}$ & $3,8 \mathrm{a}$ & $3,84 \mathrm{a}$ & $1,48 \mathrm{a}$ \\
Moti Amarelo & $38,58 \mathrm{a}$ & $3,7 \mathrm{a}$ & $3,93 \mathrm{a}$ & $1,65 \mathrm{a}$ \\
ANA 7007 & $31,53 \mathrm{c}$ & $3,8 \mathrm{a}$ & $3,93 \mathrm{a}$ & $1,48 \mathrm{a}$ \\
AN Cambará & $34,66 \mathrm{~b}$ & $3,8 \mathrm{a}$ & $3,80 \mathrm{a}$ & $1,40 \mathrm{a}$ \\
\hline \hline Primeira & $32,55 \mathrm{a}$ & $4,1 \mathrm{a}$ & $3,97 \mathrm{a}$ & $2,39 \mathrm{a}$ \\
Segunda & $33.66 \mathrm{a}$ & $4,4 \mathrm{a}$ & $3,95 \mathrm{a}$ & $1,76 \mathrm{~b}$ \\
Terceira & $33,65 \mathrm{a}$ & $3,3 \mathrm{~b}$ & $3,70 \mathrm{a}$ & $1,01 \mathrm{c}$ \\
Quarta & $34,35 \mathrm{a}$ & $3,3 \mathrm{~b}$ & $3,82 \mathrm{a}$ & $0,85 \mathrm{c}$ \\
\hline C.V. \% & 12,26 & 8,72 & 7,07 & 15,51 \\
D.M.S. & 2,43 & 0,03 & 0,30 & 0,25 \\
\hline
\end{tabular}

Médias seguidas pela mesma letra minúscula na coluna para cultivares e épocas não diferem entre si pelo teste de Tukey a $5 \%$ de probabilidade.

Observando ainda na Tabela 4, para o diâmetro do colmo observou-se que não houve diferença significativa na interação época e genótipo. Para os genótipos não houve diferença significativa, no entanto para as épocas de semeaduras houve diferença sendo que a primeira e segunda época o diâmetro do colmo foi maior, já para a terceira e quarta época de semeadura o diâmetro do colmo observado foram os menores entre as épocas.

O número médio de folhas observado não obteve diferença significativa na interação época e genótipo, observando também tanto entre épocas de semeadura e entre genótipos, o número médio de folhas não obteve diferença significativa.

O número de perfilho não obteve diferença significativa na interação época e genótipos, observou-se também que os genótipos avaliados não se diferiram significativamente, no entanto observou-se que a primeira época de semeadura, foi à época de maior número de perfilho, a terceira e quarta época a de menor número de perfilho.

A segunda avalição foi realizada aos sessenta dias após a emergência das plantas, Tabela 4, sendo as seguintes características avaliadas: altura de planta, diâmetro do colmo, número de folhas, e número de perfilho.

Para o diâmetro médio do colmo não obteve diferença significativa na interação época e genótipo, em relação aos genótipos não obtiveram diferencia significativa, já em relação as épocas de semeadura a primeira e segunda época o diâmetro médio do colmo foi maior para essas épocas, na quarta época de semeadura observou-se o menor diâmetro médio do colmo (tabela 4).

Tabela 4. Valores de $\mathrm{p}>\mathrm{F}$ e teste de comparação de médias para altura de plantas, diâmetro do colmo, número de folhas e número de perfilho avaliados aos 60 DAE dos cultivares de arroz em função de épocas de semeadura. Registro-SP, ano agrícola 2012/13. 


\begin{tabular}{|c|c|c|c|c|}
\hline \multirow[t]{2}{*}{ Teste $\mathrm{F}$} & Altura $(\mathrm{cm})$ & Diâmetro $(\mathrm{mm})$ & Folhas (un) & $\begin{array}{l}\text { Perfilhos } \\
\text { (un) }\end{array}$ \\
\hline & & \multicolumn{3}{|l|}{$p>F$} \\
\hline Genótipo (c) & 0,0343 & 0,0763 & 0,0397 & 0,0362 \\
\hline Época (e) & 0.0023 & 0,0000 & 0,1327 & 0,0000 \\
\hline$c^{*} e$ & 0.0021 & 0,0890 & 0,1200 & 0,0518 \\
\hline Moti Branco & - & $5,7 \mathrm{a}$ & $4,08 \mathrm{~b}$ & $1,81 \mathrm{~b}$ \\
\hline Moti Amarelo & - & $5,7 \mathrm{a}$ & $4,36 a b$ & $2,11 \mathrm{a}$ \\
\hline ANA 7007 & - & $5,6 \mathrm{a}$ & $4,31 \mathrm{ab}$ & $2,05 a b$ \\
\hline AN Cambará & - & 5,9 a & $4,41 \mathrm{a}$ & $2,03 a b$ \\
\hline Primeira & - & 6,4 a & $4,13 a$ & $2,33 a$ \\
\hline Segunda & - & 6,3 a & $4,43 a$ & $2,15 a b$ \\
\hline Terceira & - & $5,6 b$ & $4,41 a$ & $2,03 \mathrm{~b}$ \\
\hline Quarta & - & $4,6 c$ & $4,20 a$ & $1,50 \mathrm{c}$ \\
\hline C.V. \% & 2,29 & 4,61 & 6,71 & 12,51 \\
\hline D.M.S. & 2,08 & 0,02 & 0,32 & 0,27 \\
\hline
\end{tabular}

Médias seguidas pela mesma letra minúscula na coluna para cultivares e épocas não diferem entre si pelo teste de Tukey a $5 \%$ de probabilidade.

Para o número médio de folha não teve diferença significativa na interação época e genótipo, o AN Cambará obteve o maior número médio de folhas, sendo que o Moti Branco o menor número médio de folhas, para as épocas de semeadura não obteve diferença significativa em relação ao número médio de folhas.

O número de perfilho não obteve diferença significativa na interação época e genótipo, o Moti Amarelo foi o genótipo de maior número de perfilho, o Moti Branco o de menor número de perfilho, a primeira época de semeadura observou-se a época de maior número de perfilho sendo que a quarta época a de número de perfilho.

Na Tabela 5, observou-se que para o genótipo Moti Branco que a altura média de planta aos sessenta dias após a emergência a quarta época de semeadura foi a menor, já para o ANA 7007 as menores média de altura de planta foram obtidas na primeira, segunda e terceira época de semeadura, para o genótipo Moti Amarelo a primeira, segunda e terceira épocas de semeaduras foram as épocas de maior altura média de planta. 
Tabela 5. Desdobramento da interação para altura de plantas em função de genótipos e épocas de semeadura, avaliado aos 60 DAE.

Altura aos 60 DAE $(\mathrm{cm})$

\begin{tabular}{lllll}
\hline Época & Moti Amarelo & Moti Branco & AN Cambará & ANA 7007 \\
\hline Primeira & $94,53 \mathrm{aA}$ & $90,53 \mathrm{bA}$ & $84,67 \mathrm{aB}$ & $59,07 \mathrm{bC}$ \\
Segunda & $94,33 \mathrm{aA}$ & $95,73 \mathrm{aA}$ & $85,47 \mathrm{aB}$ & $71,23 \mathrm{aC}$ \\
Terceira & $94,26 \mathrm{aA}$ & $93,87 \mathrm{abA}$ & $83,07 \mathrm{aB}$ & $73,27 \mathrm{aC}$ \\
Quarta & $77,00 \mathrm{bA}$ & $66,07 \mathrm{cC}$ & $78,67 \mathrm{bA}$ & $71,80 \mathrm{aB}$ \\
\hline D.M.S. & 2,08 & & &
\end{tabular}

Médias seguidas pela mesma letra minúscula na vertical ou maiúscula na horizontal não diferem significativamente entre si pelo teste de Tukey a $5 \%$ de probabilidade.

Para a altura aos noventa dias após a emergência das plantas, Tabela 6, não houve diferença significativa na interação época e genótipo, o Moti Branco e Moti Amarelo foram os genótipos de maior altura média de plantas, sendo o ANA 7007 a menor altura, entretanto a segunda e terceira épocas obteve a maior altura, sendo a quarta época a de menor altura média de planta.

Tabela 6. Valores de p>F e teste de comparação de médias para altura de plantas, diâmetro do colmo, numero de folhas e numero de perfilhos avaliados aos 90 DAE dos cultivares de arroz em função de épocas de semeadura. Registro-SP, 2012/13.

\begin{tabular}{|c|c|c|c|c|c|}
\hline \multirow{3}{*}{ Teste F } & \multicolumn{2}{|l|}{ Clorofila } & \multirow{2}{*}{$\begin{array}{l}\text { Diâmetro } \\
(\mathrm{mm})\end{array}$} & \multirow{2}{*}{$\begin{array}{l}\text { Folhas } \\
\text { (un) }\end{array}$} & \multirow[b]{2}{*}{ Perfilhos (un) } \\
\hline & f) & Altura $(\mathrm{cm})$ & & & \\
\hline & & \multicolumn{4}{|l|}{$p>F$} \\
\hline Genótipos (c) & 0,0000 & 0,0000 & 0,0006 & 0,0514 & 0,0004 \\
\hline Época (e) & 0,0000 & 0,0002 & 0,0000 & 0,0000 & 0,0000 \\
\hline$c^{*} \mathrm{e}$ & 0,0001 & 0,1772 & 0,3074 & 0,1200 & 0,1056 \\
\hline Moti Branco & - & $102,52 \mathrm{a}$ & $0,67 a$ & $4,53 \mathrm{a}$ & $1,90 \mathrm{~b}$ \\
\hline Moti Amarelo & - & $105,33 \mathrm{a}$ & $0,58 \mathrm{~b}$ & $4,75 \mathrm{a}$ & $2,31 \mathrm{a}$ \\
\hline ANA 7007 & - & $79,96 \mathrm{c}$ & $0,61 a b$ & $4,55 a$ & $2,08 a b$ \\
\hline AN Cambará & - & $94,55 \mathrm{~b}$ & $0,67 a$ & $4,77 \mathrm{a}$ & $2,26 a$ \\
\hline Primeira & - & $94,81 \mathrm{ab}$ & $0,64 \mathrm{a}$ & $4,16 \mathrm{~b}$ & $2,03 \mathrm{~b}$ \\
\hline Segunda & - & 98,53 a & $0,67 a$ & $4,78 \mathrm{a}$ & $2,30 \mathrm{a}$ \\
\hline Terceira & - & $99,81 \mathrm{a}$ & $0,68 a$ & $4,96 \mathrm{a}$ & $2,50 \mathrm{a}$ \\
\hline \multirow[t]{2}{*}{ Quarta } & - & $89,21 \mathrm{~b}$ & $0,53 b$ & $4,70 \mathrm{a}$ & $1,74 \mathrm{c}$ \\
\hline & 3,25 & & & & \\
\hline C.V. \% & 0,05 & 5,82 & 8,07 & 5,51 & 10,57 \\
\hline D.M.S. & & 6,18 & 0,05 & 0,28 & 0,25 \\
\hline
\end{tabular}

Médias seguidas pela mesma letra minúscula na coluna para cultivares e épocas não diferem entre si pelo teste de Tukey a 5\% de probabilidade.

O diâmetro médio do colmo, Tabela 6, não houve diferença significativa na interação época e genótipo, o Moti Branco e AN Cambará foram os genótipos de maior diâmetro médio do 
colmo, sendo que o Moti Amarelo obteve o menor diâmetro, entre as épocas de semeadura a primeira, segunda e terceira épocas foram as épocas de maior diâmetro médio do colmo, a quarta época a de menor diâmetro.

Para o número médio de folhas não houve diferença significativa na interação épocas e genótipos, os genótipos também não se diferenciaram entre si em relação ao número médio de folhas, a segunda, terceira e quarta épocas de semeadura foram as épocas onde foi possível verificar o maior número médio de folhas, sendo a primeira época a de menor número médio de folhas (Tabela 6).

Para o número de perfilho na Tabela 6 , não houve diferença significativa na interação épocas e genótipos, os genótipos que obtiveram maior número de perfilho foram o Moti Amarelo e AN Cambará, já o Moti Branco foi o genótipo de menor número de perfilho, em relação às épocas de semeadura a segunda e terceira épocas foram as que obtiveram o maior número de perfilho, e a quarta época o menor número de perfilho.

Na Tabela 7 estão discriminadas as avaliações feitas no momento da colheita da cultura do arroz, realizado neste experimento.

Em relação à altura das plantas na colheita não houve diferença significativa entre genótipos e épocas de semeadura. O Moti Amarelo e Moti Branco demonstraram a maior altura de planta na colheita, ANA 7007 a menor altura. As épocas de semeaduras que demonstraram maior altura foram a segunda e terceira época, a semeadura realizada na primeira época demonstrou a menor altura de plantas (tabela 7).

Para semeadura realizada no mês de novembro e dezembro verificou-se a maior altura de plantas, fato este que difere dos resultados obtidos por Trettel (2012), a autora relata que a semeadura realizada em novembro proporciona planta de arroz com maior altura. A autora cita ainda que a primeira época de semeadura foi a que proporcionou plantas com menor altura, e também verificou que os genótipos Moti Branco e Moti Amarelo foram os que mais se desenvolveu em altura, resultados estes corroborando com os dados obtidos neste trabalho (tabela 7). 
Tabela 7. Valores de p>F e teste de comparação de médias para altura de plantas, diâmetro do colmo, número de folhas, número de perfilhos, quantidade de colmos e panículas por metro quadrado avaliados no momento da colheita dos cultivares de arroz em função de épocas de semeadura. Registro-SP, ano agrícola 2012/13.

\begin{tabular}{|c|c|c|c|c|c|c|}
\hline \multirow[t]{2}{*}{ Teste F } & $\begin{array}{l}\text { Altura } \\
(\mathrm{cm})\end{array}$ & $\begin{array}{l}\text { Diâmetro } \\
\text { (mm) }\end{array}$ & $\begin{array}{l}\text { Folhas } \\
\text { (un) }\end{array}$ & $\begin{array}{l}\text { Perfilhos } \\
\text { (un) }\end{array}$ & $\begin{array}{l}\text { Colmo } \\
\text { por } \mathrm{m}^{2} \\
\text { (un) }\end{array}$ & $\begin{array}{l}\text { Panículas } \\
\text { por } \mathrm{m}^{2} \\
\text { (un) }\end{array}$ \\
\hline & \multicolumn{5}{|c|}{$p>F$} & \\
\hline Genótipo (c) & 0,0000 & 0,0029 & 0,0046 & 0,0685 & 0,0439 & 0,0181 \\
\hline Época (e) & 0,0190 & 0,0000 & 0,0000 & 0,000 & 0,0000 & 0,0027 \\
\hline$c^{*} e$ & 0,0943 & 0.2886 & 0,0750 & 0,0992 & 0,2103 & 0,1200 \\
\hline Moti Branco & 105,92 a & $0,67 a$ & $4,60 \mathrm{~b}$ & $2,01 \mathrm{a}$ & $246,42 \mathrm{c}$ & $213,33 b$ \\
\hline Moti Amarelo & 110,31 a & $0,65 a b$ & $4,80 a b$ & $2,20 \mathrm{a}$ & $255,94 \mathrm{c}$ & $12,45 \mathrm{~b}$ \\
\hline ANA 7007 & $81,92 \mathrm{c}$ & $0,61 b$ & $4,53 \mathrm{~b}$ & $2,01 \mathrm{a}$ & $\begin{array}{l}268,56 \\
a b\end{array}$ & $220,71 b$ \\
\hline AN Cambará & $96,75 b$ & $0,69 a$ & $4,90 \mathrm{a}$ & $2,18 \mathrm{a}$ & $279,28 a$ & $240,47 \mathrm{a}$ \\
\hline Primeira & $94,75 \mathrm{~b}$ & $0,65 \mathrm{~b}$ & $4,26 \mathrm{~b}$ & $1,93 \mathrm{c}$ & $244,99 \mathrm{~b}$ & $178,80 \mathrm{c}$ \\
\hline Segunda & $100,43 \mathrm{a}$ & $0,69 a b$ & $4,80 a$ & $2,20 \mathrm{~b}$ & $296,23 \mathrm{a}$ & $239,04 \mathrm{a}$ \\
\hline Terceira & 101,22 a & $0,72 a$ & $4,86 a$ & $2,48 a$ & 287,13 a & $223,80 \mathrm{a}$ \\
\hline Quarta & $98,51 a b$ & $0,56 \mathrm{c}$ & $4,90 \mathrm{a}$ & $1,80 \mathrm{c}$ & $237,85 b$ & $206,42 b$ \\
\hline C.V. \% & 5,16 & 7,77 & 5,44 & 10,55 & 7,25 & 6,35 \\
\hline D.M.S. & 5,65 & 0,05 & 0,28 & 0,24 & 23,15 & 15,65 \\
\hline
\end{tabular}

Médias seguidas pela mesma letra minúscula na coluna para cultivares e épocas não diferem entre si pelo teste de Tukey a $5 \%$ de probabilidade.

O diâmetro do colmo na colheita não obteve diferença significativa na interação épocas e genótipos (Tabela 7). O genótipo AN Cambará e Moti Branco foram os que demonstraram maior diâmetro do colmo, o ANA 7007 o menor diâmetro, em relação às épocas de semeadura a terceira época de semeadura foi a de maior diâmetro médio do caule e a quarta época a de menor diâmetro (Tabela 7).

Fonseca et al., (2007) classifica o diâmetro do colmo em: 1 . Fina - menor que $4 \mathrm{~mm} ; 2$. Média - de 4,1 á 5,0 mm; 3. Grossa - maior que 5,1 mm.

Sendo que o diâmetro médio do colmo, dos genótipos em estudo nas quatro épocas de semeaduras foi de 0,61 a 0,69 mm, já para as épocas de semeaduras foram de 0,56 á 0,72 mm do diâmetro do colmo, sendo assim considerados como Fina, segundo Fonseca et al., (2007). Possibilitando a postura mais ereta da planta, reduzindo o grau de acamamento (Tabela 7). 
O genótipo AN Cambará proporcionou o maior número de folhas no momento da colheita, o ANA 7007 e o Moti Branco obtiveram os menores número de folhas, a segunda, terceira e primeira épocas de semeadura apresentaram maiores numero de folhas, sendo a primeira época com o menor numero de folhas (Tabela 7).

O número de perfilho não obteve diferença significativa na interação épocas e genótipos, a terceira época demonstrou um maior número de perfilho, a primeira e quarta época com o menor número de perfilho (Tabela 7).

O AN Cambará obteve o maior número de colmos por metro quadrado, o Moti Branco e Moti Amarelo apresentaram o menor número de colmos por metro quadrado. A segunda e terceira época de semeadura proporcionou o maior número de colmo, a primeira e quarta o menor número de colmos (Tabela 7).

O maior número de panículas por metro quadrado foi representado pelo AN Cambará, a segunda e terceira épocas de semeadura também proporcionaram o maior número de panículas, sendo a primeira semeadura de menor valor (Tabela 7).

Os dados obtidos no momento da colheita como produtividade, perfilhamento útil por metro, peso de 100 grãos e número de grãos por panículas, estão representados na Tabela 7 .

O peso de 100 grãos não teve diferença significativa entre época e cultivar, o Moti Amarelo e Moti Branco obteve maior peso em 100 grãos, o ANA 7007 e AN Cambará os menores pesos entre os genótipos (tabela 8).

Tabela 8. Valores de $\mathrm{p}>\mathrm{F}$ e teste de comparação de médias para perfilhamento útil, produtividade de grãos, quantidade de grãos por panícula e peso de grãos no momento da colheita dos cultivares de arroz em função de épocas de semeadura. Registro-SP, ano agrícola 2012/13.

\begin{tabular}{|c|c|c|}
\hline Teste F & $\begin{array}{l}\text { Perfilh. útil } \mathrm{m}^{2} \\
\text { (un) }\end{array}$ & Produtividade $(\mathrm{kg} / \mathrm{ha})$ \\
\hline Genótipo (c) & 0,0920 & 0,0303 \\
\hline Época (e) & 0,0020 & 0,0021 \\
\hline$c^{*} e$ & 0,0021 & 0,9064 \\
\hline Moti Branco & - & $3.048,57 \mathrm{~b}$ \\
\hline Moti Amarelo & - & $3.184,52 \mathrm{ab}$ \\
\hline ANA 7007 & - & $3.685,71 \mathrm{ab}$ \\
\hline AN Cambará & - & $3.783,33 \mathrm{a}$ \\
\hline Primeira & - & $3.241,67 \mathrm{bc}$ \\
\hline Segunda & - & $4.295,24 \mathrm{a}$ \\
\hline Terceira & - & $3.652,38 a b$ \\
\hline Quarta & - & $2.612,85 \mathrm{c}$ \\
\hline C.V. $\%$ & 7,39 & 18,00 \\
\hline D.M.S. & 6,32 & 689,58 \\
\hline
\end{tabular}

Médias seguidas pela mesma letra minúscula na coluna para cultivares e épocas não diferem entre si pelo teste de Tukey a $5 \%$ de probabilidade.

O genótipo AN Cambara obteve a maior produtividade entre os genótipos, sendo o Moti Branco de menor produtividade. A segunda e terceira época de semeadura mostraram-se mais 
produtivas em relação às outras épocas, enquanto a quarta época mostrou-se a de menor produtividade.

Wrege et al., (2008) verificou que os meses que proporcionaram maior floração, consequentemente resultando em uma maior produtividade para o estado do Paraná, foram Outubro e Novembro. Trettel (2012) indica que as épocas de maior produtividade para o estado de São Paulo para semeadura são Novembro e Dezembro. Neste estudo as épocas de semeadura de novembro e dezembro, foram às épocas que obtiveram a maior produtividade corroborando com os da autora Trettel (2012),

A semeadura realizada no mês de janeiro a produtividade foi a menor comparada com as outras épocas de semeadura, devido a grande quantidade de chuva no período da semeadura até a germinação assim prejudicando-a da semente e pela queda do índice médio de precipitação, prejudicando o enchimento dos grãos devido ao déficit hídrico no mês de abril, consequentemente resultando em uma menor produtividade.

Observou-se o maior perfilhamento útil na terceira e quarta época de semeadura, sendo que a segunda época obteve o menor perfilhamento útil, para os genótipos Moti Branco e Moti Amarelo a segunda época de semeadura foi a épocas de menor perfilhamento útil (Tabela 9).

Tabela 9. Desdobramento da interação do número de perfilhamento útil das plantas de arroz, para quatro genótipos em quatro épocas de semeadura, obtidos na colheita.

\begin{tabular}{lllll}
\hline \multicolumn{1}{l}{ Perfilhamento útil (\%) } & \multicolumn{3}{l}{} \\
\hline Época & Moti Branco & Moti Amarelo & ANA 7007 & AN Cambará \\
\hline \hline Primeira & $67,11 \mathrm{bAB}$ & $75,79 \mathrm{aA}$ & $69,93 \mathrm{bAB}$ & $58,31 \mathrm{aB}$ \\
Segunda & $75,62 \mathrm{abBC}$ & $71,68 \mathrm{aC}$ & $88,93 \mathrm{aA}$ & $86,41 \mathrm{aAB}$ \\
Terceira & $73,89 \mathrm{abA}$ & $82,61 \mathrm{aA}$ & $78,22 \mathrm{abA}$ & $83,89 \mathrm{aA}$ \\
Quarta & $80,28 \mathrm{aA}$ & $80,63 \mathrm{aA}$ & $83,66 \mathrm{aA}$ & $75,84 \mathrm{aA}$ \\
\hline D.M.S. & 6,32 & & &
\end{tabular}

Médias seguidas pela mesma letra minúscula na vertical ou maiúscula na horizontal não diferem significativamente entre si pelo teste de Tukey a $5 \%$ de probabilidade.

A época de semeadura interfere diretamente na produtividade, sendo considerada assim de suma importância a escolha da melhor época de semeadura em relação à precipitação média hídrica e temperatura média.

\section{CONCLUSÃO}

A partir dos resultados obtidos e nas condições de condução deste estudo pode-se concluir que:

$\checkmark$ Os genótipos Moti Branco e Moti Amarelo produziram grãos mais granados.

$\checkmark$ Os genótipos Moti Amarelo e AN Cambará destacaram-se com o maior perfilhamento útil.

$\checkmark$ A segunda época de semeadura proporcionou maior produtividade para todos os genótipos. 


\section{REFERÊNCIAS BIBLIOGRÁFICAS}

LUZZARDI, R. et al. Avaliação preliminar da produtividade em campo e qualidade industrial de híbridos de arroz no Rio Grande do Sul. In: 4.Congresso Brasileiro de Arroz Irrigado,; 26, REUNIÃO DA CULTURA DO ARROZ IRRIGADO, 2005, Santa Maria, RS. Anais... Santa Maria: SOSBAl, 2005. v.1, p.70-72. 2005.

SHEEHY, J.E. et al. (Eds). Charting new pathways to $C_{4}$ rice. Los Baños: International Rice Research Institute, $422 p$, 2007.

GUIMARÃES, C.M.; FAGERIA, N.; BARBOSA FILHO, M. P.; Como a planta de arroz se desenvolve. Encarte de informações Agronômicas, no 99. Setembro, 2002.

CRUSCIOL, C. A. C. et al. Produção e qualidade fisiológica de sementes de arroz de terras altas em função da disponibilidade hídrica. Revista Brasileira de Sementes, Londrina, v. 23, n. 2, p. 287-293, 2001.

STEINMETZ, S.; SILVA, S. C.; SANTANA, N. M. P. Clima. In: SANTOS, A. B.; STONE, L. F.; VIEIRA, N. R. A. A cultura do arroz no Brasil. Santo Antônio de Goiás: Embrapa arroz e Feijão. cap. 5, p. 117-160, 2006.

REICHARDT, K. Relações solo - água - planta para algumas culturas. In: A água em Sistemas Agrícolas. São Paulo, Editora Manole LTDA, p.157 - 171. 1987.

RAIJ, B. van; CANTARELLA, H.; QUAGGIO, J.A. \& FURLANI, A.M.C. Recomendações de calagem e adubação para o estado de São Paulo. Campinas, Instituto Agronômico de Campinas, 1997.

BRASIL. Ministério da Agricultura, Pecuária e Abastecimento. Regras para Análise de Sementes. Ministério da Agricultura, Pecuária e Abastecimento. Secretaria de Defesa Agropecuária. Brasília, DF: Mapa/ACS, 2009. 395p.

AGRONORTE PESQUISAS E SEMENTES: características. <Disponível em: http://www.agronorte.com.br/duplaaptidao/caracteristicas>. Acessado em 10 out 2013.

TRETTEL, J. S. Avaliação de Genótipos de arroz submetidas a épocas de semeadura em Registro - SP. 2012, p. 23-37. Trabalho de Conclusão de Curso (Graduação em Agronomia UNESP Registro/SP) Campus Exp. De Registro, UNESP, Registro/SP, 2012.

FONSECA, J. R. et al. Descrição morfológica, agronômica, fenológica e culinária de alguns tipos especiais de arroz (Oryza sativa L.). Embrapa Arroz e Feijão, 2007.

FORNASIERI FILHO, D.; FORNASIERI, J. L. Manual da cultura do arroz. Jaboticabal: Funep, 589 p. 2006.

WREGE, M. S., et al.; Determinação das melhores épocas de semeadura do arroz de sequeiro, Oryza sativa, no Estado do Paraná. Acta Scientiarum Agronomy, v. 23, p. 1179-1183, 2008. 